\title{
Nb-based MXenes for Li-Ion Battery Applications
}

\author{
Jiajie Zhu ${ }^{1}$, Alexander Chroneos ${ }^{2,3, a}$ and Udo Schwingenschlögl ${ }^{1, b}$ \\ ${ }^{1}$ PSE Division, KAUST, Thuwal 23955-6900, Kingdom of Saudi Arabia \\ ${ }^{2}$ Department of Materials, Imperial College, London SW7 2AZ, United Kingdom \\ ${ }^{3}$ Faculty of Engineering and Computing, Coventry University, Priory Street, \\ Coventry CV1 5FB, United Kingdom \\ ${ }^{a}$ Email: alexander.chroneos@imperial.ac.uk \\ ${ }^{b}$ Email: udo.schwingenschlogl@kaust.edu.sa
}

October 29, 2015

\begin{abstract}
Li-ion batteries depend critically on the stability and capacity of the electrodes. In this respect the recently synthesized two-dimensional MXenes are promising materials, as they combine an excellent Li-ion capacity with very high charging rates. We employ density functional theory to investigate the impact of $\mathrm{Li}$ adsorption on the structural and electronic properties of monolayer $\mathrm{Nb}_{2} \mathrm{C}$ and $\mathrm{Nb}_{2} \mathrm{CX}_{2}$. The $\mathrm{Li}$ ions are predicted to migrate easily on the pristine MXene due to a diffusion barrier of only $36 \mathrm{meV}$, whereas larger diffusion barriers are obtained for the functionalized MXenes.
\end{abstract}

Keywords: $\mathrm{Nb}_{2} \mathrm{C}$, MXene, Battery 


\section{Introduction}

Besides graphene, the quickly growing family of two-dimensional materials includes boron nitride, ${ }^{1}$ transition metal chalcogenides, ${ }^{2}$ and metal oxides, ${ }^{3}$ for example, and recently also the socalled MXenes. ${ }^{4-7}$ MXenes are early transition metal carbides and/or carbonitrides ${ }^{8}$ that can be prepared by selective etching of the $\mathrm{A}$ metal from the three-dimensional $\mathrm{M}_{n+1} \mathrm{AX}_{n}$ phases ( $n$ : integer, M: early transition metal, A: group 13-16 element, and X: C and/or N). They have hexagonal symmetry (space group P63/mmc) and are typically characterized by a combination of both ceramic (high decomposition or melting temperature, high elastic stiffness, and good machinability) and metallic (high thermal shock resistance and good thermal and electrical conductivities) features, resulting from the stacking of $n$ "ceramic" MX layer(s) separated by the "metallic" A layer.

There are many potential applications for MXenes, for example in catalysts, sensors, conductive reinforcement fillers for polymers, electronic and optoelectronic devices, and electrodes of supercapacitors for electrical energy storage. ${ }^{9-14}$ Importantly, MXenes have been identified as candidate materials for Li-ion batteries. For example, the Li storage capacity of $\mathrm{Ti}_{3} \mathrm{C}_{2}$ is comparable with commercial graphite electrodes $(372 \mathrm{mAh} / \mathrm{g}) .{ }^{15}$ In addition, a small Li diffusion barrier enables high cycling rates and most metallic MXenes show a higher electrical conductivity than other two-dimensional materials. ${ }^{16}$

Although many MXenes have been synthesized, including $\mathrm{Ti}_{2} \mathrm{C},\left(\mathrm{Ti}_{0.5} \mathrm{Nb}_{0.5}\right)_{2} \mathrm{C}, \mathrm{Ti}_{3} \mathrm{C}_{2}$, $\mathrm{Ti}_{3} \mathrm{CN}, \mathrm{Ta}_{4} \mathrm{C}_{3}, \mathrm{Nb}_{2} \mathrm{C}, \mathrm{V}_{2} \mathrm{C}$, and $\left(\mathrm{V}_{0.5} \mathrm{Cr}_{0.5}\right)_{3} \mathrm{C}_{2},{ }^{4,17}$ only the titanium carbides have been investigated intensively to obtain insight into the excellent material performance. ${ }^{15,18-21}$ For $\mathrm{V}_{2} \mathrm{C}$ a much higher capacity of $941 \mathrm{mAh} / \mathrm{g}$ as compared to the experimental value of $260 \mathrm{mAh} / \mathrm{g}$ has been predicted theoretically. ${ }^{22}$ As compared to the widely studied $\mathrm{M}_{3} \mathrm{X}_{2}$-type compound, $\mathrm{M}_{2} \mathrm{X}$-type compound can store more Li per gram (thus having a higher capacity) because the surface-to-volume ratio is larger. While a high capacity combined with a high cycling rate has been reported also for $\mathrm{Nb}_{2} \mathrm{C},{ }^{17}$ this material has received little attention so far. Therefore, we present in the following theoretical insight into the applicability of $\mathrm{Nb}_{2} \mathrm{C}$ in Li-ion batteries. Because $\mathrm{Nb}_{2} \mathrm{C}$ can be functionalized by $\mathrm{O}, \mathrm{F}$, and $\mathrm{OH}$ due to the presence of $\mathrm{HF}$ and $\mathrm{H}_{2} \mathrm{O}$ during the preparation, ${ }^{23}$ we consider the effects of these functional groups on the Li adsorption. 
pristine color.
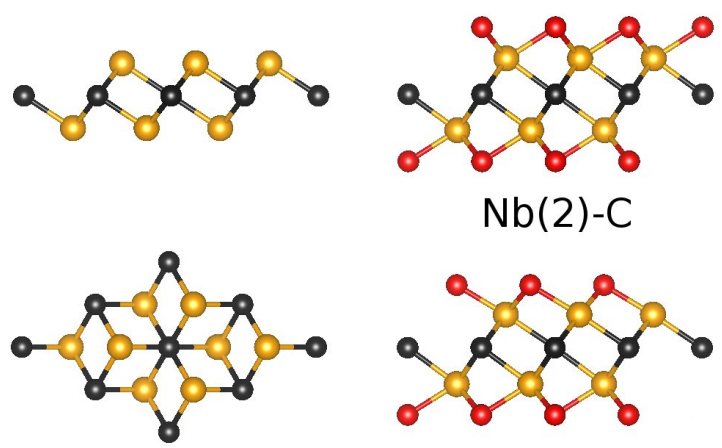

$\mathrm{Nb}(2)-\mathrm{C}$

C-C

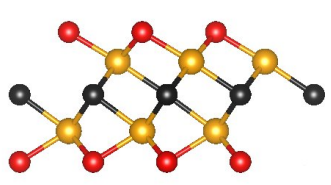

$\mathrm{Nb}(2)-\mathrm{Nb}(2)$

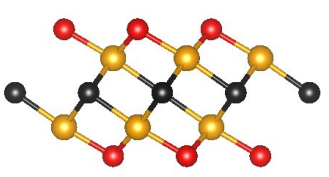

$\mathrm{Nb}(1)-\mathrm{Nb}(2)$

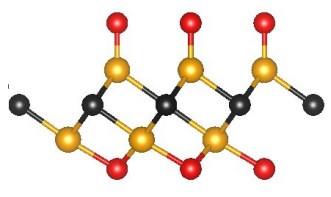

$\mathrm{Nb}(1)-\mathrm{C}$

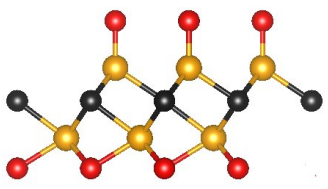

$\mathrm{Nb}(1)-\mathrm{Nb}(1)$

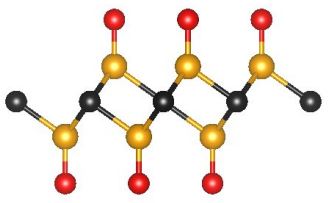

Figure 1: Structures of $\mathrm{Nb}_{2} \mathrm{C}$ (side and top views) and $\mathrm{Nb}_{2} \mathrm{CX}_{2}$ (top views) for different locations of the functional group (red). The $\mathrm{Nb}$ and $\mathrm{C}$ atoms are shown in yellow and black

\section{Computational method}

Our theoretical framework is density functional theory, using the projector augmented wave method of the Vienna Ab-initio Simulation Package. ${ }^{24}$ The generalized gradient approximation of Perdew, Burke and Ernzerhof is employed for the exchange-correlation potential and the long range van der Waals interaction is taken into account by the DFT-D3 approach ${ }^{25}$ (which is not critical for the following evaluations, since the relevant properties are determined by much stronger chemical interactions). The cut-off energy for the plane wave basis functions is set to $500 \mathrm{eV}$ and an energy criterion of $10^{-6} \mathrm{eV}$ is selected in the iterative solution of the Kohn-Sham equations. All the structures are relaxed until the residual forces on the atoms have declined to less than $0.01 \mathrm{eV} / \AA$. Brillouin zone integrations are performed on $6 \times 6 \times 1$ and $12 \times 12 \times 1 \mathrm{k}$-meshes, respectively, for the geometry optimization and electronic structure calculations. A $2 \times 2$ supercell of monolayer $\mathrm{Nb}_{2} \mathrm{C}$ is used together with a vacuum layer of $15 \AA$ thickness to avoid unphysical interaction between images due to the periodic boundary conditions. A climbing image nudged elastic band method is employed to investigate the energy barriers of Li diffusion, with 7 to 9 images between the initial and final configurations, and to calculate the minimum energy migration paths. ${ }^{26}$

\section{Results and discussion}

Figure 1 shows the structures of $\mathrm{Nb}_{2} \mathrm{C}$ and $\mathrm{Nb}_{2} \mathrm{CX}_{2}$. The $\mathrm{X}$ group can be located on top of a $\mathrm{C}$ atom, a $\mathrm{Nb}(1)$ atom (top $\mathrm{Nb}$ layer), and a $\mathrm{Nb}(2)$ atom (bottom $\mathrm{Nb}$ layer), on both sides of the 
Table 1: Distance from the $\mathrm{Nb}(1)$ atom to the functional group, which is located on top of the $\mathrm{C}, \mathrm{Nb}(1)$, or $\mathrm{Nb}(2)$ atoms.

\begin{tabular}{c|ccc} 
& $\mathrm{C}$ & $\mathrm{Nb}(1)$ & $\mathrm{Nb}(2)$ \\
\hline $\mathrm{Nb}-\mathrm{O}$ & $2.14 \AA$ & $1.72 \AA$ & $2.09 \AA$ \\
$\mathrm{Nb}-\mathrm{F}$ & $2.28 \AA$ & $1.88 \AA$ & $2.29 \AA$ \\
$\mathrm{Nb}-\mathrm{OH}$ & $2.25 \AA$ & $1.90 \AA$ & $2.27 \AA$
\end{tabular}

MXene. Thus a total of six configurations has to be considered. We will refer in the following to these configurations using the nomenclature defined in Figure 1. For $\mathrm{Nb}_{2} \mathrm{C}$ the in-plane lattice constant turns out to be $3.086 \AA$, which agrees well with the experimental value of 3.107 $\AA^{27}$ and other theoretical values, ${ }^{28,29}$ and the Nb-C bond length to be $2.16 \AA$. Configuration $\mathrm{Nb}(2)-\mathrm{Nb}(2)$ has the lowest total energy for all functional groups, confirming Ref. 30. We note that the $\mathrm{Nb}(1)-\mathrm{F}$ and $\mathrm{Nb}(1)-\mathrm{OH}$ bond lengths are similar and both larger than the $\mathrm{Nb}(1)-\mathrm{O}$ bond length, reflecting the different oxidation states of the functional groups.

We find that the energetically favorable site for Li adsorption is located on top of $\mathrm{C}$. The stability of this configuration is determined by the formation energy with respect to a reference material,

$$
E=E_{\text {combined }}-E_{\text {MXene }}-E_{\text {reference }}
$$

where $E_{\text {combined }}, E_{\mathrm{MXene}}$, and $E_{\text {reference }}$ are the total energies of the combined system in the lowest energy structure, the MXene without $\mathrm{Li}$, and the reference material. For a single $\mathrm{Li}$ atom on $\mathrm{Nb}_{2} \mathrm{C}$ and $\mathrm{Nb}_{2} \mathrm{CX}_{2}(\mathrm{X}=\mathrm{O}, \mathrm{F}$ and $\mathrm{OH})$ we obtain formation energies of $-0.71,-2.28$, -1.61 , and $0.51 \mathrm{eV}$, respectively, with respect to bulk $\mathrm{Li}$. The positive value for $\mathrm{Nb}_{2} \mathrm{C}(\mathrm{OH})_{2}$ reflects instability, in agreement with related theoretical results, ${ }^{31}$ and points to the formation of $\mathrm{Li}$ clusters. The value for $\mathrm{Nb}_{2} \mathrm{CO}_{2}$ is significantly more negative than that for $\mathrm{Nb}_{2} \mathrm{CF}_{2}$, because the oxidation state of $\mathrm{O}$ is more negative than that of $\mathrm{F}$. The stabilities of the $\mathrm{O}$ and $\mathrm{F}$ groups are investigated as $\mathrm{LiF}$ and $\mathrm{Li}_{2} \mathrm{O}$ could be formed. Moreover, a 3:1 ratio of $\mathrm{O}$ and F functional groups will be addressed as it is motivated by the experiment. ${ }^{17}$ The $\mathrm{O}$ group associated with two $\mathrm{Li}$ atoms results in formation energies of -2.47 and $-2.53 \mathrm{eV}$ for $\mathrm{Nb}_{2} \mathrm{CO}_{2}$ and $\mathrm{Nb}_{2} \mathrm{CO}_{1.5} \mathrm{~F}_{0.5}$, respectively, with respect to $\mathrm{Li}_{2} \mathrm{O}$, reflecting stability. Furthermore, we obtain for the $\mathrm{F}$ group associated with one $\mathrm{Li}$ atom values of 0.09 and $-0.54 \mathrm{eV}$ for $\mathrm{Nb}_{2} \mathrm{CF}_{2}$ and $\mathrm{Nb}_{2} \mathrm{CO}_{1.5} \mathrm{~F}_{0.5}$, respectively, with respect to $\mathrm{LiF}$. The instability of the $\mathrm{F}$ group for $\mathrm{Nb}_{2} \mathrm{CF}_{2}$ agrees with results reported for $\mathrm{V}_{2} \mathrm{C}$ and $\mathrm{Ti}_{3} \mathrm{C}_{2} \cdot{ }^{22,32} \mathrm{On}$ the other hand, the strong interaction 

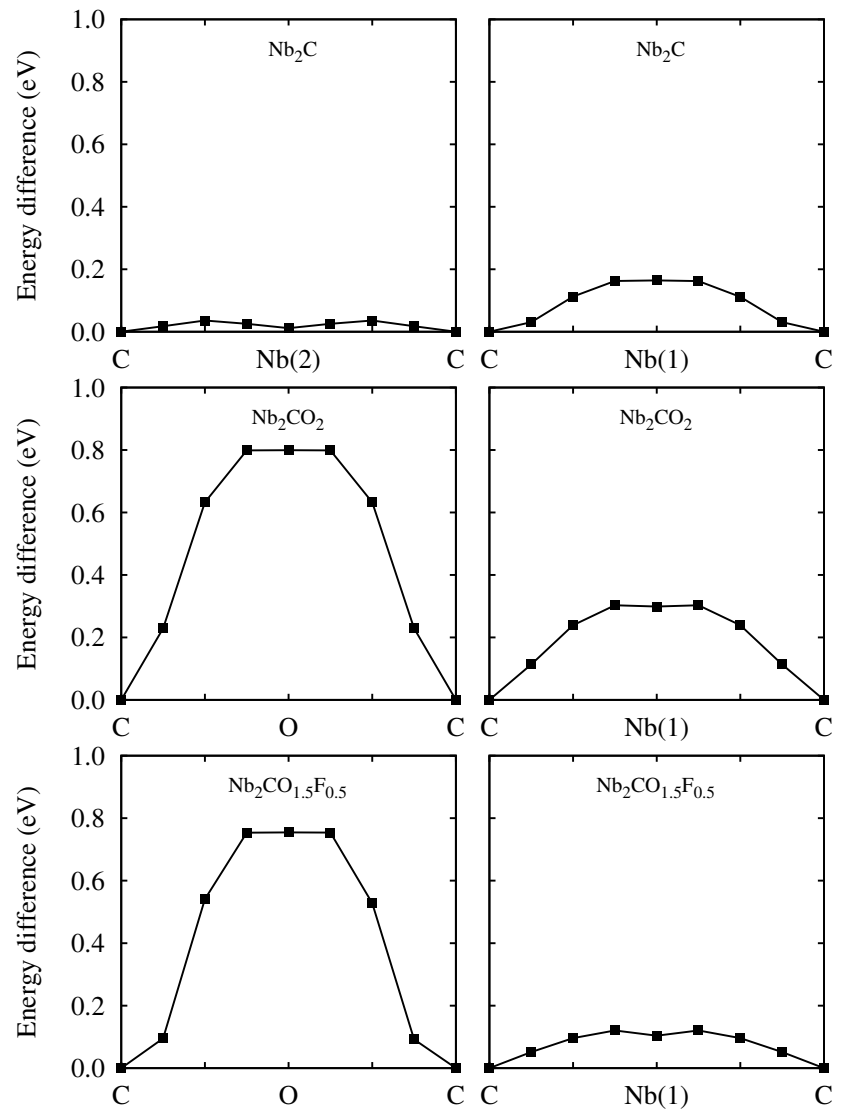

Figure 2: Diffusion barriers for $\mathrm{Li}$ on $\mathrm{Nb}_{2} \mathrm{C}$ and $\mathrm{Nb}_{2} \mathrm{CX}_{2}$.

with neighbouring $\mathrm{O}$ atoms stabilizes the $\mathrm{F}$ group on $\mathrm{Nb}_{2} \mathrm{CO}_{1.5} \mathrm{~F}_{0.5}$. Due to the above results, the $\mathrm{F}$ and $\mathrm{OH}$ groups will not be considered in the following.

Diffusion barriers for Li migration are addressed in Figure 2, considering the three migration paths defined in Figure 3. All migration paths turn out to consist of almost straight segments. For $\mathrm{Nb}_{2} \mathrm{C}$ path $\mathrm{C}-\mathrm{C}$ converges to path $\mathrm{C}-\mathrm{Nb}(2) / \mathrm{O}-\mathrm{C}$ and for $\mathrm{Nb}_{2} \mathrm{CO}_{2}, \mathrm{Nb}_{2} \mathrm{CF}_{2}$, and $\mathrm{Nb}_{2} \mathrm{CO}_{1.5} \mathrm{~F}_{0.5}$ path $\mathrm{C}-\mathrm{C}$ converges to path $\mathrm{C}-\mathrm{Nb}(1)-\mathrm{C}$. For $\mathrm{Nb}_{2} \mathrm{C}$ path $\mathrm{C}-\mathrm{Nb}(2) / \mathrm{O}-\mathrm{C}$ has the lowest diffusion barrier of $36 \mathrm{meV}$ with the transition state located on top of the $\mathrm{C}-\mathrm{Nb}(2)$ bond. A local minimum is located on top of the $\mathrm{Nb}(2)$ atom with $12 \mathrm{meV}$ higher energy. The diffusion barrier along path $\mathrm{C}-\mathrm{Nb}(1)-\mathrm{C}$ amounts to $160 \mathrm{meV}$. In the cases of the functionalized MXenes path C-Nb(1)-C has the lowest diffusion barrier with values of 300 and $120 \mathrm{meV}$ for $\mathrm{Nb}_{2} \mathrm{CO}_{2}$ and $\mathrm{Nb}_{2} \mathrm{CO}_{1.5} \mathrm{~F}_{0.5}$, respectively, while for path $\mathrm{C}-\mathrm{Nb}(2) / \mathrm{O}-\mathrm{C}$ we obtain values of 800 and $750 \mathrm{meV}$. The transition state is located almost on top of the $\mathrm{Nb}(1)$ atom for $\mathrm{Nb}_{2} \mathrm{CO}_{2}$ and $\mathrm{Nb}_{2} \mathrm{CO}_{1.5} \mathrm{~F}_{0.5}$. Therefore, easy migration is achieved on $\mathrm{Nb}_{2} \mathrm{C}$, whereas all functional groups significantly increase the diffusion barriers. This fact can be understood in terms of the charge 


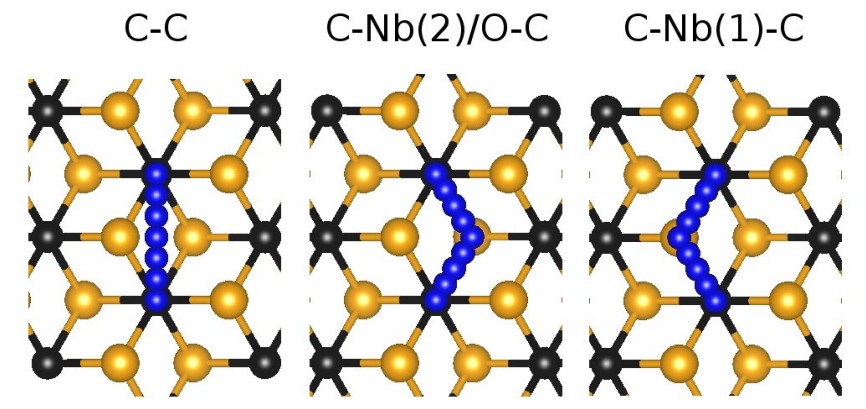

Figure 3: Migration paths under consideration. Note that paths $\mathrm{C}-\mathrm{Nb}(2) / \mathrm{O}-\mathrm{C}$ and $\mathrm{C}-\mathrm{Nb}(1)-\mathrm{C}$ are not symmetric in the presence of functional groups, which are not shown in the figure.
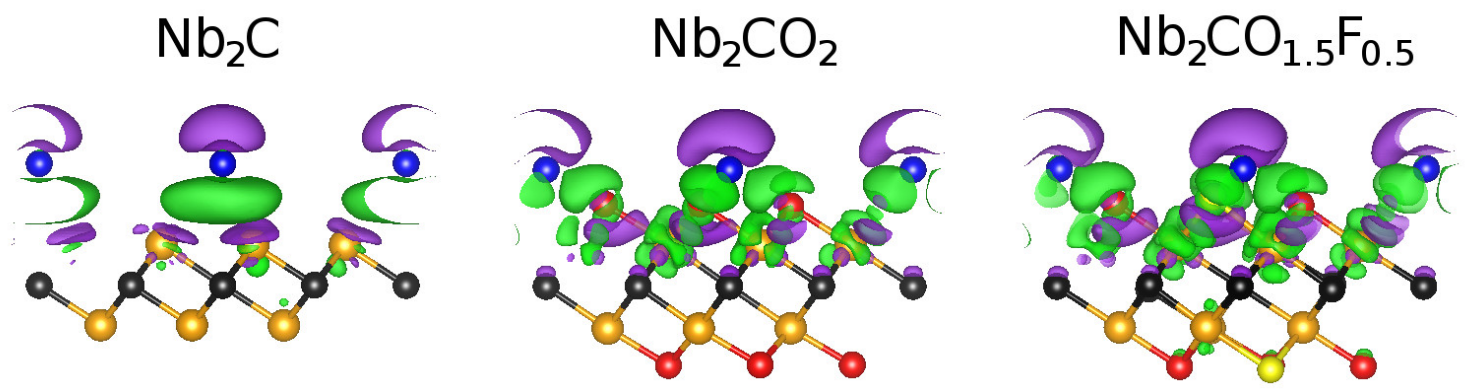

Figure 4: Ground state charge redistribution due to the interaction with Li. Green/purple color represents charge accumulation/depletion, where the isosurfaces refer to an isovalue of $1.8 \times 10^{-3}$ electrons/bohr ${ }^{3}$. The Nb, C, O, F, and Li atoms are shown in yellow, black, red, light yellow and blue color.

density differences due to the interaction with Li atoms,

$$
\Delta \rho=\rho_{\text {combined }}-\rho_{\text {MXene }}-\rho_{\mathrm{Li}}
$$

as illustrated in Figure 4 . Here $\rho_{\text {combined }}, \rho_{\text {MXene, }}$, and $\rho_{\mathrm{Li}}$ are the charge densities of the combined system, MXene, and Li atom, respectively. While there is no qualitative difference between the results for the functionalized MXenes, we observe a strongly reduced interaction for bare $\mathrm{Nb}_{2} \mathrm{C}$. This picture is supported by the densities of states shown in Figure 5 . No Li $2 s$ contributions are found below $-2 \mathrm{eV}$ for bare $\mathrm{Nb}_{2} \mathrm{C}$ in contrast to the cases of the functionalized MXenes, again demonstrating weak interaction. We note that the metallic nature of $\mathrm{Nb}_{2} \mathrm{C}$ and $\mathrm{Nb}_{2} \mathrm{CX}_{2}$ as shown in Figure 5 is highly desirable for application in Li-ion batteries.

In order to calculate the $\mathrm{Li}$ specific capacities of the different materials, we consider the maximal Li adsorption. Adsorption beyond a monolayer on both sides of the MXene is not addressed, since Li clusters are hard to decompose during the recharge process due to the large binding energy. We find that $\mathrm{Nb}_{2} \mathrm{C}$ can adsorb up to $9 \mathrm{Li}$ atoms per $2 \times 2$ supercell, 


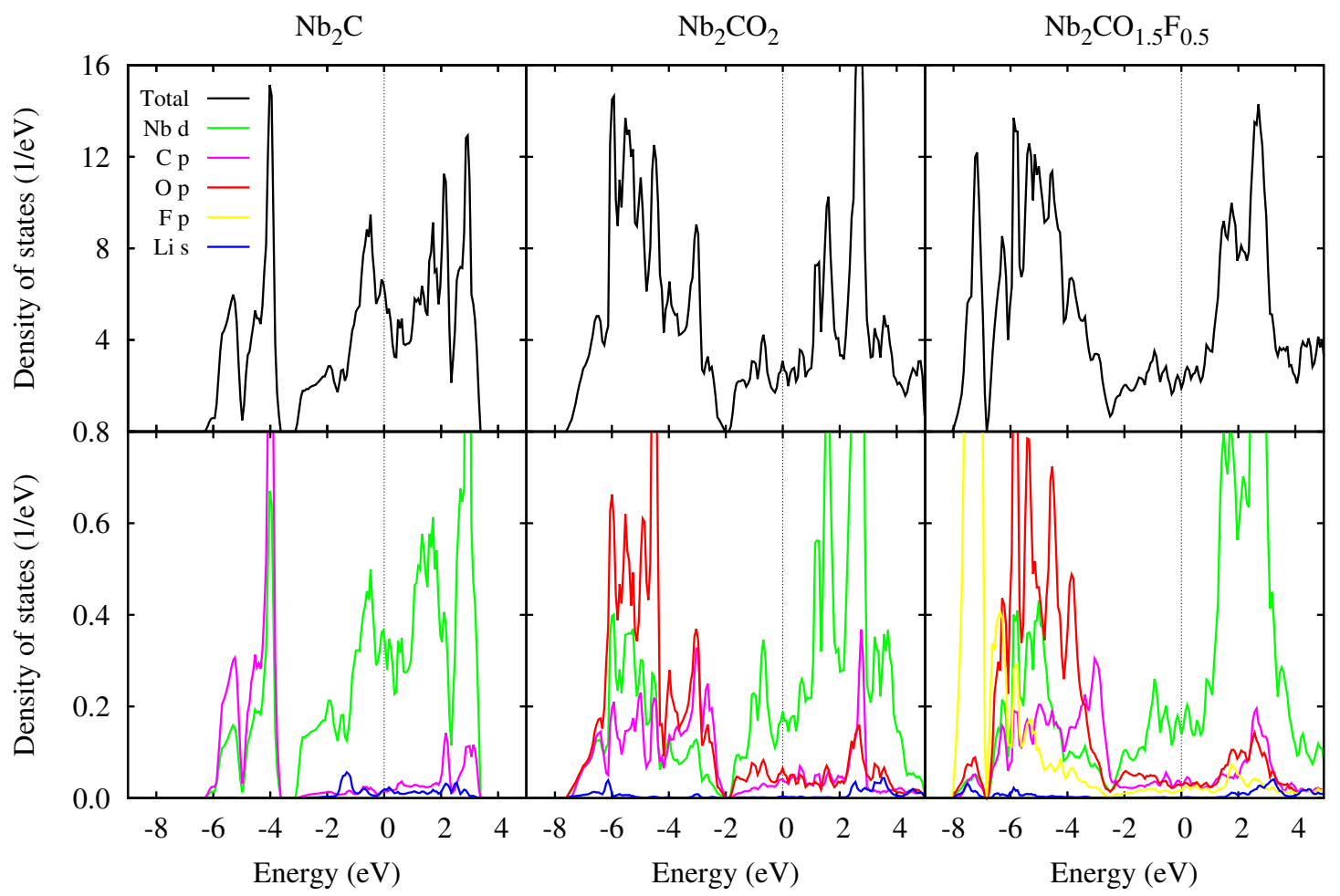

Figure 5: Densities of states after Li decoration. The Fermi level is set to zero.

8 located on top of or below $\mathrm{C}$ and the last one on top of $\mathrm{Nb}(2)$. This corresponds to a maximal $\mathrm{Li}$ concentration of 2.25 atoms per unit cell. $\mathrm{Nb}_{2} \mathrm{CO}_{2}$ can accommodate $10 \mathrm{Li}$ atoms per $2 \times 2$ supercell, 6 on one side and 4 on the other side, which corresponds to a maximal Li concentration of 2.5 atoms per unit cell. In contrast to $\mathrm{Nb}_{2} \mathrm{C}$, here two Li ions are located on top of $\mathrm{Nb}(2)$ without forming a Li cluster (strong interaction with the MXene). Although the $\mathrm{F}$ group is stable on $\mathrm{Nb}_{2} \mathrm{CO}_{1.5} \mathrm{~F}_{0.5}$ with a $\mathrm{Li}$ atom attached, $\mathrm{LiF}$ will be formed when more $\mathrm{Li}$ atoms are adsorbed. $\mathrm{Nb}_{2} \mathrm{CO}_{1.5} \mathrm{~F}_{0.5}$ can accomodate only two $\mathrm{Li}$ atoms, one on each side.

We obtain specific capacities of 305 and $292 \mathrm{mAh} / \mathrm{g}$ for $\mathrm{Nb}_{2} \mathrm{C}$ and $\mathrm{Nb}_{2} \mathrm{CO}_{2}$, whereas the corresponding value for the $\mathrm{O} / \mathrm{F}$ system is only $29 \mathrm{mAh} / \mathrm{g}$. Although $\mathrm{F}$ is inclined to react with $\mathrm{Li}$ to $\mathrm{LiF}$, further $\mathrm{Li}$ atoms can be adsorbed. Hence, the experimental value of $170 \mathrm{mAh} / \mathrm{g}$ can be attributed to the mixture of $\mathrm{O}$ and $\mathrm{F}$ groups. ${ }^{17}$ However, LiF obstructs the Li migration and thus leads to a degraded performance for high cycling rates. The calculated specific capacity is comparable to the high value of $\mathrm{Ti}_{3} \mathrm{C}_{2}(320 \mathrm{mAh} / \mathrm{g}) .{ }^{32}$ 


\section{Conclusions}

The structural and electronic properties of Li decorated $\mathrm{Nb}_{2} \mathrm{C}$ and $\mathrm{Nb}_{2} \mathrm{CX}_{2}$ have been investigated by first principles calculations. The favorable adsorption sites of the functional groups have been determined. Since Li will form clusters on $\mathrm{Nb}_{2} \mathrm{C}(\mathrm{OH})_{2}$ and $\mathrm{LiF}$ on $\mathrm{Nb}_{2} \mathrm{CF}_{2}$ and $\mathrm{Nb}_{2} \mathrm{CO}_{1.5} \mathrm{~F}_{0.5}, \mathrm{OH}$ and $\mathrm{F}$ functional groups must be avoided in battery applications. We find the by far lowest diffusion barrier for $\mathrm{Li}$ on $\mathrm{Nb}_{2} \mathrm{C}$. Specific capacities of 305 and $292 \mathrm{mAh} / \mathrm{g}$ are obtained for $\mathrm{Nb}_{2} \mathrm{C}$ and $\mathrm{Nb}_{2} \mathrm{CO}_{2}$, respectively. Since the diffusion barrier for $\mathrm{Nb}_{2} \mathrm{CO}_{2}$ is high, $\mathrm{Nb}_{2} \mathrm{C}$ without functionalization turns out to be the most promising electrode material for Li-ion batteries.

\section{Acknowledgment}

Research reported in this publication was supported by the King Abdullah University of Science and Technology (KAUST).

\section{References}

[1] Novoselov, K. S.; Jiang, D.; Schedin, F.; Booth, T. J.; Khotkevich, V. V.; Morozov, S. V.; Geim, A. K. Proc. Natl. Acad. Sci. U.S.A. 2005, 102, 10451-10453.

[2] Jeong, S.; Yoo, D.; Jang, J.-T.; Kim, M.; Cheon, J. J. Am. Chem. Soc. 2012, 134, 1823318236

[3] Ma, R.; Sasaki, T. Adv. Mater. 2010, 22, 5082-5104.

[4] Eames, C.; Islam, M. S. J. Am. Chem. Soc. 2014, 136, 16270-16276.

[5] Lei, J.-C.; Zhang, X.; Zhou, Z. Front. Phys. 2015, 10, 276-286.

[6] Zhang, X.; Ma, Z.; Zhao, X.; Tang, Q.; Zhou, Z. J. Mater. Chem. A 2015, 3, 4960-4966.

[7] Tang, Q.; Zhou, Z. Prog. Mater. Sci. 2013, 58, 1244-1315.

[8] Naguib, M.; Mochalin, V. N.; Barsoum, M. W.; Gogotsi, Y. Adv. Mater. 2014, 26, 9921005. 
[9] Zhang, X.; Xu, J.; Wang, H.; Zhang, J.; Yan, H.; Pan, B.; Zhou, J.; Xie, Y. Angew. Chem. Int. Ed. 2013, 52, 4361-4365.

[10] Hu, Q.; Sun, D.; Wu, Q.; Wang, H.; Wang, L.; Liu, B.; Zhou, A.; He, J. J. Phys. Chem. A 2013, 117, 14253-14260.

[11] Wang, F.; Yang, C.; Duan, C.; Xiao, D.; Tang, Y.; Zhu, J. J. Electrochem. Soc. 2015, 162, B16-B21.

[12] Lee, Y.; Hwang, Y.; Cho, S. B.; Chung, Y.-C. Phys. Chem. Chem. Phys. 2014, 16, 2627326278.

[13] Ma, Z.; Hu, Z.; Zhao, X.; Tang, Q.; Wu, D.; Zhou, Z.; Zhang, L. J. Phys. Chem. C 2014, 118, 5593-5599.

[14] Gao, Y.; Wang, L.; Li, Z.; Zhou, A.; Hu, Q.; Cao, X. Solid State Sci. 2014, 35, 62-65.

[15] Er, D.; Li, J.; Naguib, M.; Gogotsi, Y.; Shenoy, V. B. ACS Appl. Mater. Inter. 2014, 6, 11173-11179.

[16] Lee, Y.; Cho, S. B.; Chung, Y.-C. ACS Appl. Mater. Inter. 2014, 6, 14724-14728.

[17] Naguib, M.; Halim, J.; Lu, J.; Cook, K. M.; Hultman, L.; Gogotsi, Y.; Barsoum, M. W. J. Am. Chem. Soc. 2013, 135, 15966-15969.

[18] Xie, Y.; Kent, P. R. C. Phys. Rev. B 2013, 87, 235441.

[19] Enyashin, A.; Ivanovskii, A. J. Solid State Chem. 2013, 207, 42-48.

[20] Zhao, S.; Kang, W.; Xue, J. J. Phys. Chem. C 2014, 118, 14983-14990.

[21] Sun, D.; Wang, M.; Li, Z.; Fan, G.; Fan, L.-Z.; Zhou, A. Electrochem. Commun. 2014, 47, 80-83.

[22] Hu, J.; Xu, B.; Ouyang, C.; Yang, S. A.; Yao, Y. J. Phys. Chem. C 2014, 118, 2427424281.

[23] Li, Z.; Wang, L.; Sun, D.; Zhang, Y.; Liu, B.; Hu, Q.; Zhou, A. Mater. Sci. Eng. B 2015, 191, 33-40. 
[24] Kresse, G.; Joubert, D. Phys. Rev. B 1999, 59, 1758-1775.

[25] Grimme, S.; Antony, J.; Ehrlich, S.; Krieg, H. J. Chem. Phys. 2010, 132, 154104.

[26] Henkelman, G.; Uberuaga, B. P.; Jnsson, H. J. Chem. Phys. 2000, 113, 9901-9904.

[27] Salama, I.; El-Raghy, T.; Barsoum, M. J. Alloy. and Compd. 2002, 347, 271-278.

[28] Wang, J.; Zhou, Y. Phys. Rev. B 2004, 69, 214111.

[29] Qian, X.; Li, Y.; He, X.; Fan, H.; Yun, S. J. Phys. Chem. Solids 2011, 72, 954-956.

[30] Khazaei, M.; Arai, M.; Sasaki, T.; Chung, C.-Y.; Venkataramanan, N. S.; Estili, M.; Sakka, Y.; Kawazoe, Y. Adv. Funct. Mater. 2013, 23, 2185-2192.

[31] Xie, Y.; DallAgnese, Y.; Naguib, M.; Gogotsi, Y.; Barsoum, M. W.; Zhuang, H. L.; Kent, P. R. C. ACS Nano 2014, 8, 9606-9615.

[32] Tang, Q.; Zhou, Z.; Shen, P. J. Am. Chem. Soc. 2012, 134, 16909-16916. 